\title{
Rapid Evolution of a Myelodysplastic Syndrome in a Case of Multiple-Myeloma: Therapy Related or Not?
}

\author{
Debord C', Touzeau $C^{2}$, Theisen $\mathrm{O}^{1}$, Béné $\mathrm{MC}^{1}$ and \\ Eveillard M* \\ ${ }^{1}$ Department of Hematology Biology, Nantes University \\ Hospital, France \\ ${ }^{2}$ Department of Hematology, Nantes University Hospital, \\ France \\ *Corresponding author: Marion Eveillard, \\ Department of Hematology Biology, Nantes University \\ Hospital, Nantes, France
}

Received: March 13, 2017; Accepted: April 06, 2017; Published: April 25, 2017

\begin{abstract}
An unusual case of concomitant lymphoid and myeloid neoplasias is presented, where a woman with a history of multiple myeloma developed pancytopenia and dysgranulopoiesis in the peripheral blood. Bone marrow examination confirmed an additional diagnosis of myelodysplastic syndrome with excess blasts. This MDS could be either linked to MM treatment or to the increased risk of $\mathrm{MM}$ patients to develop secondary myelodysplasia. Interestingly, MDS-specific del( $5 q)$ and a $t(2 ; 12)$ were observed on the myeloid karyotype. This case highlights that bone marrow examination is mandatory when cytopenias are disclosed on blood cell counts.
\end{abstract}

Keywords: Multiple myeloma, Myelodysplasia; Bone marrow

\section{Case Presentation}

A 66-year-old woman was diagnosed with an IgA-kappa multiple myeloma (MM) without del $(17 \mathrm{p})$ or $\mathrm{t}(4 ; 14)$ as assessed by Fluorescence In Situ Hybridization. She had received a first line of therapy associating bortezomib, thalidomide and dexamethasone followed by autologous stem-cell transplantation (auto-SCT). She relapsed one year later and received a regimen of lenalidomide and dexamethasone. She developed two thromboembolic episodes and was then enrolled in a clinical trial comprising carfilzomib. After the second cycle, three years after the initial diagnosis and two years after auto-SCT, she had a routine check of peripheral blood (PB) parameters. This complete blood count disclosed pancytopenia with normocytic anemia $(10.4 \mathrm{~g} / \mathrm{dL}, 87 \mathrm{fL})$, thrombopenia $\left(108 \times 10^{9} / \mathrm{L}\right)$ and neutropenia $\left(1.43 \times 10^{9} / \mathrm{L}\right)$. The $\mathrm{PB}$ smear showed $3 \%$ blasts (Figure 1A) and major dysgranulopoiesis (Figure 1B, 1C). These abnormal features, possibly heralding impending relapse, prompted to perform a bone marrow (BM) aspiration. BM smears were rich with $4.5 \%$ of abnormal plasma-cells (Figure 1D, 1E), 2\% blasts and major erythroblastosis (62.5\%). Morphological examination also disclosed multilineage dysplasia with monolobated megakaryocytes (Figure 1D) and dysgranulopoiesis characterized by cytoplasmic hypogranularity and nuclear hypolobation (Figure 1E, 1F). Dyserythropoiesis was also observed, with the presence of bilobated nuclei (Figure $1 \mathrm{G}$ ). Conventional cytogenetics was performed on BM and detected $a \operatorname{del}(5 \mathrm{q})$ and $\mathrm{t}(2 ; 12)(\mathrm{q} 12 ; \mathrm{q} 13)$. This led, in addition to the partially controlled $\mathrm{MM}$, to a diagnosis of myelodysplastic syndrome with excess blasts type 1 (MDS-EB1) according to the 2016 WHO classification [1].

This led to exclude the patient from the trial and carfilzomib was stopped. It was decided to only provide the patient with red blood cells transfusions for her MDS-EB1. For MM, she was switched to daratumumab. Unfortunately, the first perfusion was complicated by an acute pulmonary edema, leading to stop the use of this antiCD38 monoclonal antibody. She receives currently bendamustine and dexamethasone.

\section{Discussion}

In this case, the observation of the newly developed myelodysplasia on $\mathrm{PB}$ smears from an MM patient prompted to perform additional cytogenetic studies that disclosed clonal hematopoiesis. Of course, flow cytometry could also have been contributive but was not performed here [2,3]. Second malignancies developing in MM patients have been sporadically reported in the literature and are considered rare events. In a large epidemiological study by Mailankody, et al. [4], which examined the records of $8740 \mathrm{MM}$ patients and 5652 patients with monoclonal gammapathy of undetermined significance (MGUS), the incidence of post-therapy acute myeloid leukemia (AML)/MDS was evaluated at $1 \%$. It was also shown by these authors to concern only M with IgG or IgA M-protein. Among possible favoring factors, high-dose melphalan involved in the procedure of auto-SCT was first suspected [5]. In the era of immunomodulating drugs (imids) and especially lenalidomide, Reece and Goswami reported MDS/AML in $2.6 \%$ of patients treated with lenalidomide for refractory/relapsed $\mathrm{MM}$, at a median of 76 months from the time of MM diagnosis [6].

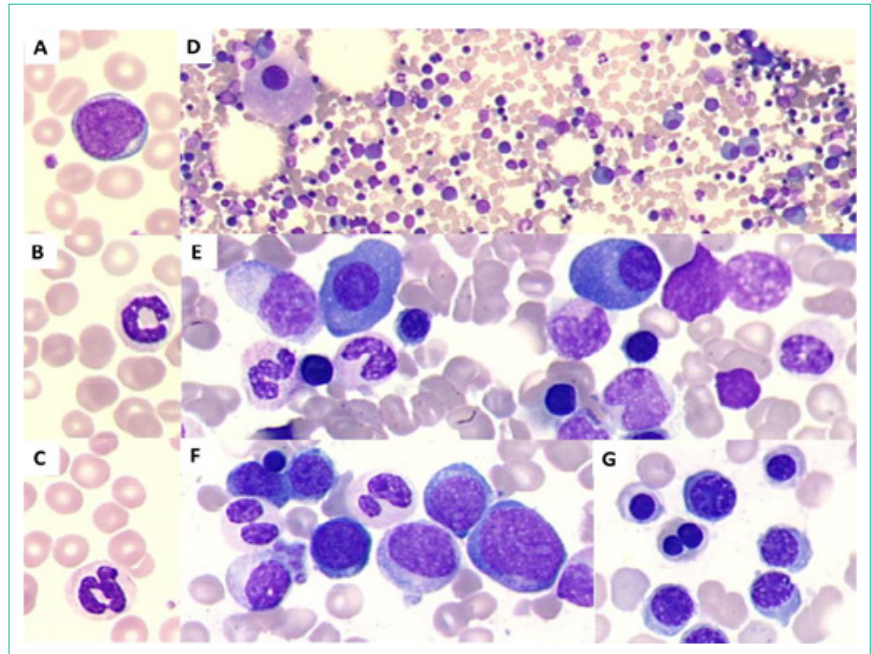

Figure 1:
Ann Hematol Oncol - Volume 4 Issue 4 - 2017 ISSN : 2375-7965 | www.austinpublishing group.com Eveillard et al. ( ) All rights are reserved
Citation: Debord C, Touzeau C, Theisen O, Béné MC and Eveillard M. Rapid Evolution of a Myelodysplastic Syndrome in a Case of Multiple-Myeloma: Therapy Related or Not?. Ann Hematol Oncol. 2017; 4(4): 1147. 
An even longer delay was reported very recently by the same group in a single institution, with a median time from diagnosis to MDS/ AML appearance of 6.7 years [7]. occurred very rapidly, barely 2 years after auto-SCT. The median delay between the initiation of therapy and the appearance of a secondary malignancy is of $\sim 45$ months in a compilation of 15 trials/studies/series [6]. In this review, the authors also debate on the role of genetic or behavioral factors, inherent to the patient, as well as risk factors associated with the specific characteristics of MM [8].

In the case reported here, where the patient indeed suffered from IgA MM, the delay was very short before diagnosing MDS-EB1. This supports the notion that clonal hematopoiesis could have been present already in the MM. Treatment-related MDS is possible in this case, but patient-related factors cannot be excluded raising the question of the development of an independent second hematological malignancy. This is supported in part by the presence of MDS-related chromosomal anomalies [del(5q) [9] and $\mathrm{t}(2 ; 12)$ [10]] in this patient. Regarding the short delay, the diagnosis was also perhaps prompted by the rapid decision to perform a control BM examination in front of cytopenias.

\section{References}

1. Arber DA, Orazi A, Hasserjian R, Thiele J, Borowitz MJ, Le Beau MM, et al The 2016 revision to the World Health Organization classification of myeloid neoplasms and acute leukemia. Blood. 2016; 127: 2391-2405

2. Matarraz S, Paiva B, Diez-Campelo M, López-Corral L, Pérez E, Mateos MV, et al. GEM Grupo Español de MM/Programa para el Estudio de la Terapéutica en Hemopatías Malignas Co-operative StudyGroups.. Myelodysplasia-associated immunophenotypic alterations of bone marrow cells in myeloma: are they present at diagnosis or are they induced by lenalidomide? Haematologica. 2012; 97: 1608-1611.
3. Matarraz S, Paiva B, Díez-Campelo $M$, Bárrena $S$, Jara-Acevedo $M$, Gutiérrez ML, et al. Immunophenotypic alterations of bone marrow myeloid cell compartments in multiple myeloma patients predict for myelodysplasiaassociated cytogenetic alterations. Leukemia. 2014; 28: 1747-1750.

4. Mailankody S, Pfeiffer RM, Kristinsson SY, Korde N, Bjorkholm M, Goldin $\mathrm{LR}$, et al. Risk of acute myeloid leukemia and myelodysplastic syndromes after multiple myeloma and its precursor disease (MGUS). Blood. 2011; 118: 4086-4092

5. Govindarajan R, Jagannath S, Flick JT, Vesole DH, Sawyer J, Barlogie B, et al. Preceding standard therapy is the likely cause of MDS after autotransplants for multiple myeloma. Br J Haematol. 1996; 95: 349-353.

6. Reece DE, Goswami RS. Incidence and characteristics of secondary myelodysplastic syndrome developing during lenalidomide-based regimens in relapsed and/or refractory multiple myeloma patients. Blood. 2010; 116: 1877.

7. Kotchetkov R, Masih-Khan E, Chu C, Atenafu EG, Chen C, Kukreti V, et al. Secondary primary malignancies during the lenalidomide-dexamethasone regimen in relapsed/refractory multiple myeloma patients. Cancer Med. 2017; 6: 3-11.

8. Thomas A, Mailankody S, Korde N, Kristinsson SY, Turesson I, Landgren O Second malignancies after multiple myeloma: from 1960s to 2010s. Blood. 2012: 119: 2731-2737.

9. Cazzola M. Myelodysplastic syndrome with isolated $5 q$ deletion (5q-syndrome). A clonal stem cell disorder characterized by defective ribosome biogenesis. Haematologica. 2008; 93: 967-972.

10. Walker A, Mrózek K, Kohlschmidt J, Rao KW, Pettenati MJ, Sterling LJ, et al. Alliance for Clinical Trials in Oncology. New recurrent balanced translocations in acute myeloid leukemia and myelodysplastic syndromes: cancer and leukemia group B 8461. Genes Chromosomes Cancer. 2013; 52: 385-401.
Ann Hematol Oncol - Volume 4 Issue 4 - 2017

ISSN : 2375-7965 | www.austinpublishinggroup.com Eveillard et al. (C) All rights are reserved
Citation: Debord C, Touzeau C, Theisen O, Béné MC and Eveillard M. Rapid Evolution of a Myelodysplastic Syndrome in a Case of Multiple-Myeloma: Therapy Related or Not?. Ann Hematol Oncol. 2017; 4(4): 1147. 